\title{
COMUNIDADES VIRTUAIS DE APRENDIZAGEM EM PERSPECTIVA
}

Simone Rocha da Conceição - UFRGS/UCDB - simone.rocha@ufrgs.br Rosimeire Martins Régis dos Santos - UCDB - profarosimeireregis@ hotmail.com

\begin{abstract}
Resumo: A modalidade de educação a distância (EAD) tem observado um grande crescimento nos últimos anos, proporcionado, sobretudo, pelo avanço das tecnologias de informação e comunicação (TIC). A EAD digital, geração atual, requer constantes investimentos em pesquisas para fomentar o desenvolvimento de massa crítica. Na perspectiva da cibercultura, este artigo propõe investigar se a utilização de comunidades virtuais de aprendizagem (CVA) como recurso metodológico pode contribuir para a promoção de uma EAD menos massificada, valorizando os interesses individuais e alterando a lógica vertical de transmissão de conteúdos para outra horizontal e colaborativa. Assim, como proposta metodológica, optou-se pela realização de uma pesquisa bibliográfica de cunho qualitativo, mediante a análise de publicações disponibilizadas em bases de dados com reconhecido valor acadêmico-científico. Dentre os resultados, constatou-se não existir consenso quanto à definição do termo CVA, esta, por sua vez, sofre adaptações de acordo com as concepções epistemológicas que aportam seu uso no âmbito de cada curso. Como conclusão, as CVAs possibilitam interações e conflitos cognitivos imprescindíveis à instauração de aprendizagens significativas.
\end{abstract}

Palavras-chaves: educação a distância; cibercultura; comunidades virtuais de aprendizagem.

\section{VIRTUAL LEARNING COMMUNITIES IN PERSPECTIVE}

\begin{abstract}
Distance learning has witnessed considerable growth in recent years, mainly due to the advancement of information and communication technologies (ICT). Digital distance learning, in its current state, requires constant investment in research in order to foster the development of a critical mass. From the perspective of cyberculture, this article proposes to investigate the use of virtual learning communities (VLC) as a methodological resource for the promotion of a less massive distance learning modality, in which individual interests are valued and the vertical logic of content transmission is changed into a horizontal and collaborative one. The methodology adopted in this project is bibliographic research, which is essentially qualitative, since the data was gathered through the analysis of publications available in databases with recognized academic and scientific value. Among the results, it was found there is no consensus for the definition of the term VLC; it is, in turn, adapted according to the epistemological concepts assumed within each course. In conclusion, VLCs allow the establishment of interactions and cognitive conflicts indispensable to the fostering of meaningful learning.
\end{abstract}

Keywords: distance learning; cyberculture; virtual learning communities.

\section{Introdução}

A Educação a Distância (EAD) é a modalidade educacional que mais cresce atualmente. No ano de 2014, segundo o Instituto Nacional de Estudos e Pesquisas Educacionais Anísio Teixeira (INEP), foram realizadas 1.341.842 matrículas nos cursos de graduação a distância, número que corresponde a pouco mais de um terço $(33,75 \%)$ do total de matrículas efetuadas nos cursos de graduação, somando-se os cursos presenciais e a distância. Paralelo a essa expansão, torna-se imprescindível o desenvolvimento de pesquisas para a formação de massa crítica, dado que o contexto atual não concebe mais um ensino verticalizado de cunho conteudista e sim que os 
estudantes desenvolvam competências que os auxiliem a ver, analisar, selecionar e interpretar o oceano de informações a sua volta. Ainda que os estudos apontem para a coexistência de diversos modelos de cursos EAD, incluindo os com ênfase em abordagens meramente conteudistas, todos são, igualmente, absorvidos pelo mercado.

No âmbito da EAD observando aspectos relativos à cibercultura, este estudo visa analisar como as comunidades virtuais de aprendizagem (CVA) podem constituir recursos metodológicos adequados às concepções epistemológicas que têm na interação $\mathrm{o}$ aspecto fundante das aprendizagens. E, ainda, como a multiplicidade de pontos de vista pode contribuir para a negociação dos sistemas de significação dos membros da comunidade.

Assim, para o desenvolvimento deste trabalho optou-se pela realização de uma pesquisa bibliográfica de cunho qualitativo e, para assegurar a qualidade dos dados coletados, foram selecionados artigos científicos, dissertações, teses e revistas especializadas em educação disponíveis para download nas plataformas Portal de Periódicos da Capes, SciELO, LUME, e Google Acadêmico, onde foram realizadas buscas pelos termos: "comunidade virtual de aprendizagem", "virtual community" $e$ "virtual learning community", obtendo um total de 530 resultados. Diante do elevado número de publicações encontradas, foi necessário definir estratégias para refinar as buscas. A primeira estratégia empregada foi a da relevância dos títulos em relação à pesquisa, em seguida foi estabelecido um limite cronológico, admitindo publicações a partir do ano de 2004. Após esses procedimentos foi realizada, ainda, uma leitura da introdução e da conclusão de todos os trabalhos, selecionando apenas aqueles que mantiveram estreita relação com o tema desta pesquisa. Restaram, assim, 39 publicações que foram lidas na íntegra e analisadas com auxílio do software Nvivo buscando compreender o fenômeno das Comunidades Virtuais de aprendizagem no âmbito da Educação a Distância no Brasil.

\section{Contextualizando a Educação a Distância}

De modo geral, considerando os estudos por correspondência, rádio e televisão, a Educação a Distância (EAD) não é, em si, nenhuma novidade. Estudos mostram que a EAD surgiu na Europa na primeira metade do século XIX se espalhando, paulatinamente, por diversos países até chegar ao Brasil em 1904 (Alves, 2011). Entretanto, conforme destaca Alves (2011), somente em 1996, com a criação da Secretaria de Educação a Distância (SEED) pelo Ministério da Educação, a EAD passou a ser oficialmente reconhecida como modalidade educacional no Brasil (Lei de Diretrizes e Bases da Educação Nacional n 9.394, de 20 de dezembro de 1996).

Ao longo da história da EAD percebemos mudanças não apenas quanto à estrutura tecnológica, mas, ainda, quanto às próprias concepções de ensino e de aprendizagem, aspectos que se encontram estreitamente relacionados com as tecnologias disponíveis em dado momento. Se, inicialmente, acreditava-se em um processo passivo de transferência do conhecimento, com o avanço da ciência cognitiva, passamos a compreender e a valorizar as interações do sujeito neste processo, i.e., como este negocia e estabelece as relações necessárias entre o que sabe e uma nova informação, para obter uma aprendizagem que lhe seja significativa. Na chamada geração digital da EAD, a distribuição massiva de informações e a simples entrega de conteúdos, aspectos característicos de outras gerações, já não são suficientes para assegurar a ocorrência de aprendizagens. Neste sentido, observamos a crescente quantidade de estudos e a formação de massa crítica sobre esta modalidade de aprendizagem. 
Cabe destacar que, inicialmente, a EAD tinha o propósito fundamental de democratizar o acesso à educação. Hoje, entretanto, o estudante que pretende ingressar nesta modalidade de ensino precisa possuir, além do computador e de acesso à internet, determinadas competências que o capacitem a transpor os entraves impostos pelo meio (softwares e hardwares), para só então usufruir o que lhe é oferecido em um ambiente virtual de aprendizagem (AVA). Aspecto que nos leva a questionar se o atual estágio da EAD democratiza, de fato, o acesso à educação (VIEIRA, 2007). Por outro lado, a EAD amplia o acesso à educação ao permitir flexibilizar tempos e espaços, ao observar e respeitar o ritmo da aprendizagem individual, ao ampliar a oferta de cursos de educação continuada, qualificação e aprimoramento profissional.

O desenvolvimento das tecnologias (em especial as de informação e de comunicação - TIC), somado ao que se convencionou chamar de Web 2.0 e em consonância com as demandas suscitadas pela sociedade em constante transformação, tem alterado substancialmente a maneira como nos relacionamos e como nos comunicamos. No contexto da EAD, as funcionalidades da Web 2.0 (blogs; wikis; podcasts etc.) permitem que diferentes formas de comunicação e interação sejam estabelecidas entre estudante/estudante, estudante/professor, estudante/conteúdos potencializando o processo de aprendizagem. Entretanto, para lograr êxito é necessário o engajamento de todos os atores envolvidos neste processo - estudantes, professores e tutores. Esses, por sua vez, deixam de ser expectadores passivos para assumir novas posições como (co) autores e (co) produtores de informações.

De acordo com a abordagem sociointeracionista de Vygotsky, são das 'interações sociais' que emergem os significados, frutos de uma dinâmica entre os sujeitos, resultado de encontros e desencontros entre diferentes níveis de conhecimento (VYGOTSKY apud SARMENTO, 2008). Essa dinâmica tenciona e força, consequentemente, a ampliação dos horizontes do saber.

Neste ponto, torna-se incontornável deixar de estabelecer relações com aspectos da cibercultura, com a necessidade de fomentar o desenvolvimento da inteligência coletiva e de questionar como as comunidades virtuais de aprendizagem (CVA) respondem a essas exigências no contexto atual da EAD.

\section{Cibercultura e Inteligência Coletiva}

Em definição dada por Lévy "a cibercultura especifica o conjunto de técnicas (materiais e intelectuais), de práticas, de atitudes, de modos de pensamento e de valor que se desenvolvem juntamente com o crescimento do ciberespaço" (LÉVY, 1999, p. 17). Quanto à origem do termo ciberespaço, esse foi cunhado pelo escritor William Gibson no seu livro Neuromancer, de 1984, trata-se, por sua vez, de um espaço estabelecido pela interconexão rizomática das redes de computadores (infraestrutura material), pelas quais fluem as informações (virtual).

O autor destaca que a velocidade praticamente inapreensível com que somos expostos ao conjunto das transformações técnicas, faz com que, "até mesmo os mais 'ligados' encontrem-se, em graus diversos, ultrapassados pela mudança." Eis aqui, segundo esse autor, "o papel principal da inteligência coletiva:" quanto mais ela se desenvolve, "melhor é a apropriação (...) das alterações técnicas, e menores são os efeitos de exclusão ou de destruição humana resultantes da aceleração do movimento tecno-social" (LEVY, 1999, pp. 28-29).

Este "novo meio de comunicação, de pensamento e de trabalho" proporcionados pelo ciberespaço permite nos articularmos coletivamente sem o "sufocamento e a divisão das inteligências." Isso implica em reconhecer que temos o 
potencial tanto para ensinar como para aprender uns com os outros, ampliando de forma recíproca as capacidades cognitivas. Assim, as "inteligências coletivas que elaboram e reelaboram seus projetos e recursos, refinam constantemente suas competências", pois ao confrontarem seus diferentes pontos de vistas, conseguem abordar o problema em sua complexidade. Entretanto, para obter êxito, é necessário "mergulhar em um ciclo constante de escuta, expressão, decisão e avaliação.” (LEVY, 1998, pp. 56 e 71).

Para Lévy, o ciberespaço é o ambiente propício para fomentar o desenvolvimento de inteligências coletivas mediante o estabelecimento de comunidades virtuais. Essas, atendendo diferentes contextos e demandas, podem ser classificadas em comunidades virtuais de prática, de investigação, de interesses, de circunstância, de propósito, de conhecimento, de aprendizagem, entre outras. Nos limites deste artigo, as reflexões que seguem referem-se às comunidades virtuais de aprendizagem.

\section{Comunidades Virtuais de Aprendizagem}

Mesmo entre os autores que se dedicam aos estudos sobre comunidades virtuais de aprendizagem (CVA) não há unanimidade quanto à definição do termo (BARAB, KLING, e GRAY; B. K. DANIEL apud PAZ, 2015) que vem sendo tomado com base no conceito de comunidade e como esse se adapta ao contexto do ciberespaço. Se, por um lado, os conceitos de comunidade e de ciberespaço apresentam aspectos mais estáticos, por outro, o mesmo não ocorre quanto às múltiplas concepções de ensino e aprendizagem que concorrem contemporaneamente. Desta forma, a apreensão do sentido do termo CVA estará condicionada às filiações epistemológicas adotadas em cada contexto.

De acordo com o sociólogo Silvio (2000), uma comunidade é, então, definida como sendo um grupo que se articula em torno de um objetivo em comum, para tanto, mantêm relações entre si, intercâmbios afetivos e informativos com vistas a alcançar um resultado (SILVIO apud AXT, 2004).

Observando a potência latente do ciberespaço para resgatar e reconstruir aspectos comunitários perdidos, Howard Rheingold, foi um dos primeiros autores a se valer do termo comunidades virtuais (CV), definindo-as, em 1993, como: "agregações sociais que surgem da Internet quando pessoas suficientes mantêm suficientes debates públicos, com suficiente sentimento humano para formar teias de relacionamento no ciberespaço" (TAJRA, 2002 apud VIEIRA, 2007, p. 43). As CV envolvem "afinidades de interesses, de conhecimentos, de projetos mútuos e valores de troca estabelecidos num processo de cooperação" (LÉVY; PALLOFF; PRATT apud SCHLEMMER, 2010, p. 151). Para Fernback e Thompson (s/d), as CV "são aquelas em que as relações sociais se estabelecem no ciberespaço através de um contato repetido num local específico, simbolicamente limitado por um tópico de interesse, tal como ocorre em um fórum" (FERNBACK e THOMPSON apud SILVA, 2008, p. 3). As CV apresentam assim, em relação a uma comunidade física e geograficamente localizada, maior independência quanto aos espaços e tempos comuns, já que as interações síncronas ou assíncronas ocorrem independentemente do local em que se encontram os membros.

O que vai diferenciar uma CVA em relação a uma CV será a ênfase dada à sua dimensão cognitiva e não a outros tipos de interesses (PAZ, 2015). Sartori e Roesler (2003) destacam que as CVA têm origem a partir do estabelecimento de objetivos comuns de aprendizagem em um determinado grupo, com ênfase no desenvolvimento de habilidades e competências (ZANK, BASSO e PASSERINO, 2008). Quando propostas institucionalmente, como no caso da EAD, as CVA passam a se organizar artificialmente e não mais mediante a livre adesão dos membros, posto que os membros 
são agrupados em um número limitado para compor uma turma, que, por sua vez, terá seu ciclo de vida vinculado à duração de um módulo, de uma disciplina ou de um curso (PAZ, 2015). Ainda no contexto da EAD, Caixeta, Ribeiro e Leite (2012) vão destacar três principais variações sobre o significado das CVA: em primeiro lugar, como "conjunto de pessoas que têm um objetivo comum; em segundo, como conjunto de pessoas que se unem para superar suas dificuldades e potencializar suas habilidades" e, em terceiro, como:

[...] conjunto de pessoas que podem ou não ter interesses em comum, mas que geram espaços de zona de desenvolvimento proximal e, portanto, de negociação, que possibilitam posicionamentos diversos na atuação dentro e fora dos ambientes virtuais de aprendizagem, de forma a construir cooperação, colaboração e reciprocidade (solidariedade) entre os participantes e para além deles (CAIXETA, RIBEIRO e LEITE, 2012, p. 374).

Junto às diversas abordagens epistemológicas encontradas na EAD, Santaella (2007) destaca a coexistência de diferentes tecnologias e que, ao contrário do que se acreditava, as novas tecnologias não suplantam necessariamente as anteriores. Neste contexto, Novak (2010, p. 38) destaca que não existe um modo único, mas sim, coexistem múltiplos modelos e se fazer EAD, com diferentes "objetivos educacionais, infraestrutura, recursos tecnológicos, projeto pedagógico, fundamentação teórica" etc. Tais aspectos justificam as distintas possibilidades de aprendizagem na EAD destacando que todas são, igualmente, absorvidas pelo mercado (BISCHOFF, 2015).

A complexificação da sociedade passa a exigir, também, uma nova maneira de ensinar e de aprender, motivo que justifica a necessidade de se repensar a educação e seus objetivos. Rheingold destaca que as CV "podem ajudar seus membros a lida com a sobrecarga das informações [...] estabelecendo um intercâmbio constante de informações úteis e relevantes entre os interessados" (RHEINGOLD apud VIEIRA, 2007, p. 46). Neste sentido, segundo Axt (2013), a adoção das CVA favorece a "produção de pensamento, produção de conhecimento, relação dialógica, interação cooperativa, capacidade de expressão e de escuta, avaliação compartilhada, autoria" (AXT, 2013, p. 40).

Quanto às CVA, adotadas como um dos recursos metodológicos na EAD, de acordo com as concepções de Lapa (2009) e de Matta e Carvalho (2008), evidencia-se que estas constituem espaços privilegiados de construção de conhecimento, sobretudo, por possibilitarem a interação entre os diferentes sujeitos (CAIXETA, RIBEIRO e LEITE, 2012). Neste sentido, Valente (2010) e Dillenbourg et al. (2003) destacam que não basta existir um grupo de pessoas interessadas em aprender para que se constitua uma CVA, mas é imprescindível a ocorrência de interação, de cooperação, e de engajamento entre os membros (VALENTE apud CAMPOS e SILVEIRA, 2013; DILLENBOURG et al., apud PAZ, 2015). Observa-se que tais aspectos têm orientado as publicações recentes envolvendo as CVA, as quais buscam analisar e refletir, sobretudo, sobre como as interações estabelecidas em uma CVA podem promover aprendizagens significativas ${ }^{1}$ e fomentar o desenvolvimento de inteligências coletivas, tal como reportado por Lévy.

\subsection{Interações e aprendizagens colaborativas}

Entre as publicações analisadas, no intuito de identificar os diversos tipos e níveis de interação, foram referidos como aportes teóricos: a Teoria de Interação Social de Piaget, a Teoria Sociointeracionista de Vygotsky, Teorias da Comunicação Pós- 
estruturalista e a Teoria dos Grupos. Assim, as interações podem ser estabelecidas entre estudante-estudante, estudante-professor, estudante-tutor e estudante-conteúdo, baseadas na comunicação bidirecional (um-um) ou multidirecional (todos-todos), podem ser, ainda, mútuas ou reativas ${ }^{2}$.

Tarouco et al (2008) sugerem algumas estratégias com vistas a estimular o desenvolvimento cognitivo dos participantes como, por exemplo, quanto à formulação de perguntas (TAROUCO et al., apud PEREIRA, 2011). Comumente, as interações estabelecidas em uma CVA são disparadas mediante provocações ${ }^{3}$ ou perturbações ${ }^{4}$ efetuadas pelo professor ou pelo tutor. Neste sentido, quando os estudantes respondem a essa provocação estabelecem interações reativas (bidirecional) e, quando as respostas se desdobram entre os membros, tendem a se tornar mútuas (multidirecionais). Diante da ocorrência de interações mútuas é possível confrontar múltiplos pontos de vista, com isso, segundo Vieira:

Há um estímulo generalizado para a aprendizagem em conjunto, renovando a paixão pela descoberta de novos mundos da educação. "A colaboração, resultado da aprendizagem em conjunto, cria uma sensação de sinergia. [...] O resultado final do conhecimento adquirido e compartilhado é muito maior do que aquele que seria gerado por meio do envolvimento individual e independente com o que se estuda". Lévy (1999) recorda que os professores também ganham nesse processo: eles aprendem ao mesmo tempo que (sic) os estudantes e atualizam continuamente seus saberes disciplinares e suas competências pedagógicas. (VIEIRA, 2007, p. 61).

Cabe destacar que o desenvolvimento da inteligência coletiva não visa "fundir as inteligências individuais em uma espécie de magna indistinto", mas promover o "processo de crescimento, de diferenciação e de retomada recíproca das singularidades" (LÉVY, 1999, p. 32). Nesse processo, encontram-se implicados, conflitos sociocognitivos ${ }^{5}$ que precisam ser (re) negociados e (re) significados, em colaboração (Vygotsky) ou cooperação (Piaget), com base no respeito mútuo.

De qualquer forma, as interações em nível ótimo não ocorrem espontaneamente a partir da simples instauração de uma CVA, é preciso criar e fomentar um ambiente favorável. Lévy aponta para a "engenharia do laço social, como sendo a arte de suscitar coletivos inteligentes e valorizar ao máximo a diversidade das qualidades humanas" (LÉVY, 1998, p. 32). Atingimos, assim, a questão da manutenção das CVA.

\subsection{Manutenção de Comunidade Virtual de Aprendizagem}

Uma das características mais importantes para a obtenção de êxito em uma CVA refere-se à conquista da confiança (LARSON e LAFASTO, 1989; KATZENBANCH e SIMTH, 1993; HANDY, 1995; MCMAHAN, 1999; KIMBLE et al., 2002 apud VIEIRA, 2007). Segundo Damiani et al. (1999), não podemos esperar que pessoas, que nunca estabeleceram contato anteriormente, passem a trabalhar juntas e a compartilhar informações a partir do momento em que se constituiu uma CVA (DAMIANI et al. apud VIEIRA, 2007). Assim como nos grupos físicos, é necessário tempo e algumas estratégias para que a confiança possa ser alcançada.

Para King (1999), "o líder do grupo desempenha papel fundamental na manutenção da coesão do grupo e na solução de problemas", seja favorecendo o desenvolvimento da iniciativa e da criatividade, seja definindo claramente os limites e os objetivos da CVA (KING apud VIEIRA, 2007, p. 52). 
Tarouco et al (2008) e Silva (2008) dão atenção especial aos usos e às formulações das perguntas como "umas das mais significativas formas de dinamizar uma comunidade, como estratégia linguística de construção do conhecimento, como estratégia de aproximação, de criação de vínculos afetivos" (TAROUCO et al., apud PEREIRA, 2011 e SILVA, 2008, pp. 215-216). Ao responder perguntas dirigidas ao professor, esse deve buscar realizar mediações pedagógicas estimulando não apenas as interações verticais, mas, sobretudo, as horizontais, posto que as últimas beneficiam a comunidade como um todo (PEREIRA, 2011).

Com o intuito de auxiliar os estudantes no processo para aprender como "interagir, colaborar e ser responsáveis pela construção de seu conhecimento," que, segundo Conrad e Donaldson (2004), não são habilidades intuitivas, os autores propõem um "modelo de 'fases de envolvimento', que progressivamente guiarão o estudante rumo à autonomia intelectual" (CONRAD e DONALDSON apud SABBATINI, 2015, p. 90).

Um aspecto que importa salientar refere-se aos diferentes modelos que analisam os 'ciclos de vida' das comunidades, amplamente referenciado por Paz (2015) no subcapítulo de sua tese "A evolução da Comunidade Virtual de Aprendizagem", de onde destaco que, "segundo Schwier (2011), as CVA modificam-se com o tempo, mas é possível prever algumas das suas mudanças fundamentais: um período de criação, de maturação e de transformação ou morte" (SCHWIER apud PAZ, 2015, p. 173).

\section{Considerações Finais}

A geração atual da EAD, chamada de digital devido ao uso intenso das Tecnologias de Informação e Comunicação (TIC), encontra-se em constante atualização, seja em decorrência do surgimento, cada vez mais frequente, de novas tecnologias, seja pelo crescente número de pesquisas que incidem sobre essa modalidade em expansão, fomentando o desenvolvimento de massa crítica.

Neste sentido, a revisão bibliográfica de cunho qualitativo proposta por este artigo visou realizar um levantamento de publicações significativas quanto ao uso de CVA no âmbito da EAD, recorrendo, para tanto, às publicações disponíveis para download em bases de dados com reconhecido valor acadêmico-científico como: o Portal de Periódicos da Capes, o SciELO, o LUME, e o Google Acadêmico.

Entre as publicações analisadas, observou-se que não existe unanimidade quanto à definição do termo CVA e, também, que não é possível afirmar que o significado do termo CVA venha sendo ampliado, sistematicamente, de uma concepção tradicional a uma pós-moderna. Assim, o entendimento sobre o termo mantém estreita relação com a abordagem epistemológica adotada pelos diversos modelos de EAD que coexistem contemporaneamente.

A este respeito, sobre a coexistência de múltiplos modelos de EAD, e de acordo com a bibliografia consultada, observamos que as novas tecnologias não suplantam necessariamente as antigas, mas todas são igualmente assimiladas e passam a coexistir. Bem como, atualmente, concorrem modelos que fazem uso intenso das TIC e outros baseados em materiais impressos de cunho conteudista (típicos da segunda e da terceira geração da EAD). Tais aspectos são atribuídos, entre outros fatores, à questão do acesso ou à falta dele.

Sob o paradigma construtivista e o sociointeracionista, enfatizados aqui, a utilização das CVA como um dos recursos metodológico da EAD, sugere que, enquanto cibercomunidades, tendem a fomentar a criação de laços entre os membros, que passam a reconhecer a possibilidade de aprendizado uns com os outros. Ao se verem implicados 
no processo de aprendizagem todos ganham inclusive o professor que tem seus saberes constantemente atualizados. Aspecto que, por sua vez, reforça o sentimento de interdependência entre os membros incidindo positivamente, desta forma, na redução das taxas de evasão (um dos problemas recorrentes nesta modalidade).

Um dos achados mais relevantes neste estudo diz respeito aos conflitos cognitivos, destacadamente importantes para a promoção de aprendizagens e para a ampliação do conhecimento. Aspecto que vai à contramão do que vem ocorrendo no âmbito do Facebook, por exemplo, que adota um sistema de recomendação que sugere pessoas e temas alinhados aos do usuário, aliado a um hábito crescente que consiste em excluir amigos ou postagens que se contrapõem ao ponto de vista do usuário. Somam-se a estes aspectos as informações descontextualizadas e descomprometidas obtidas mediante a prática de zapping na rede. Entretanto, ao reduzir ou excluir possíveis conflitos prestamos um desserviço ao desenvolvimento de inteligências coletivas. Contrariando alguns teóricos da área da cognição que veem na interação a oportunidade de confronto e de negociação entre diferentes perspectivas para a ampliação do conhecimento, este tipo de serviço e práticas supracitados, vem, lentamente, minando as possibilidades de embate entre as diferenças. Se, por um lado, os serviços de recomendação visam separar o joio do trigo, i.e., auxiliar a filtrar o conteúdo importante do restante, em um mar de informações, por outro lado, poderão se estabelecer (se já não o são) como ferramentas de cibercontrole.

Diante do exposto, quando bem utilizadas enquanto recurso metodológico, as CVA podem contribuir para tornar o ensino e a aprendizagem da EAD mais individualizados, considerando as demandas e as necessidades dos estudantes e não apenas a distribuição de conteúdos programáticos estabelecido institucionalmente sem a devida contextualização. Contribuindo, assim, para o desenvolvimento das competências imprescindíveis ao contexto atual, i.e., que o estudante possa elaborar e reelaborar significações mediante a negociação em colaboração com os demais membros da comunidade.

\footnotetext{
${ }^{1}$ A expressão parece ter caído no senso comum, entretanto, aprendizagem significativa é o conceito central da teoria de aprendizagem de David Ausubel, publicada em 1963, com contribuições de Joseph Novak a partir de 1970. Para Ausubel, uma aprendizagem torna-se significativa à medida que uma nova informação se relaciona com o conhecimento prévio do estudante de maneira não-arbitrária e substantiva. Segundo Moreira (1997, s/p.), a não-arbitrariedade refere-se à maneira como uma informação potencialmente significativa relaciona-se com conhecimentos especificamente relevantes, chamados por Ausubel de subsunçores que, por sua vez, servem de ancoragem para a incorporação, compreensão e fixação de novos conhecimentos. Quanto à substantividade significa que o que vai ser incorporado, como novo conhecimento, à estrutura cognitiva é a substância, a essência do novo conhecimento e não um conjunto de palavras empregadas para expressá-la. Isso implica na capacidade de explicar um conceito ou proposição de múltiplas maneiras, mantendo a equivalência do significado.

${ }^{2}$ Tipologias identificadas e analisadas mais detidamente por Primo (2000).

${ }^{3}$ Segundo Demo (2002), “o charme da comunicação não é o que comunica frontalmente, mas o que faz pela metade, insinua, provoca, deixa em suspense. O que se comunica frontalmente implica petição de obediência em sua linearidade canhestra, enquanto o que se comunica pela insinuação provoca o sujeito que colabora e reinterpreta a seu modo" (DEMO apud SCHERER, 2008, p. 4).

${ }^{4}$ Segundo Backes, "no contexto educacional, principalmente na formação de educadores, é importante o desenvolvimento de práticas pedagógicas problematizadoras (perturbação). Assim, os espaços digitais virtuais de convivência se efetivam na compensação do problema (perturbação), na legitimidade do outro e na relação não hierárquica entre seres humanos que são coensinantes e coaprendentes" (BACKES, 2015, p. 453).

${ }^{5}$ Segundo Almeida (1993), "conflitos cognitivos podem ser deliberadamente provocados pelos professores (...) quando eles apelam à exploração de materiais, à análise de situações, à resolução de problemas" (ALMEIDA apud SILVA, 2015, p. 11).
} 


\section{Referências Bibliográficas}

ALVES, L. Educação a distância: conceitos e história no Brasil e no mundo. RBAAD, Vol. 10, 2011. Disponível em: 〈http://seer.abed.net.br/edicoes/2011/Artigo_07.pdf>. Acesso em: 26 Maio 2016.

AXT, M. Estratégias de educação : Comunidades virtuais de aprendizagem. KLERING, L. R. (Org.). Temas contemporâneos sobre gestão universitária. Florianópolis : Bookess, 2013. Disponível em: 〈http://hdl.handle.net/10183/76083>. Acesso em: 26 Maio 2016.

AXT, M. Comunidades virtuais de aprendizagem. Informática na Educação: teoria \& prática, Porto Alegre, v.7, n. 1, p. 111-116, jan./jun. 2004. Disponível em:

<http://seer.ufrgs.br/index.php/InfEducTeoriaPratica/article/view/4943/3344>. Acesso em: 26 Maio 2016.

BACKES, Luciana. O hibridismo tecnológico digital na configuração do espaço digital virtual de convivência: formação do educador. Revista Inter Ação, [S.1.], v. 40, n. 3, p. 435-456, dez. 2015. ISSN 1981-8416. Disponível em: <https://www.revistas.ufg.br/interacao/article/view/ 35419/19866>. Acesso em: 26 Maio 2016. doi: http://dx.doi.org/10.5216/ia.v40i3.35419.

BISCHOFF, T. G. O aprender como acontecimento na EAD : análise de práticas e experiências. Centro de Estudos Interdisciplinares em Novas Tecnologias da Educação. Programa de Pós-Graduação em Informática na Educação/UFRGS, 2015. Tese de doutorado. Disponível em: <http://hdl.handle.net/ 10183/128891>. Acesso em: 26 Maio 2016.

CAIXETA, J. E.; RIBEIRO, L. B. L.; LEITE, M. C. M. Um estudo teórico sobre as comunidades de aprendizagem na educação a distância. In: Anais $3^{\circ}$ Simpósio Educação e Comunicação, 17 a 19 setembro, 2012, p, 370-384. Disponível em:

〈http://geces.com.br/simposio/anais/anais-2012/Anais-370-384.pdf $\rangle$. Acesso em: 26 Maio 2016.

CAMPOS, M. B.; SILVEIRA, M. S. Do planejamento à ação: elaboração de dinâmicas de trabalho em grupo em ambientes virtuais como estratégia à mediação e à interação. CARNEIRO, M. L. F. e TURCHIELO, L. B. (Orgs.). Educação a distância e tutoria : considerações pedagógicas e práticas. Porto Alegre : Evangraf, 2013, p, 74-94. Disponível em: <http://hdl.handle.net/10183/109246>. Acesso em: 26 Maio 2016.

CARNEIRO, M. L. F. Educação a distância : Histórias e tecnologias. In: CARNEIRO. M. L. F. e TURCHIELO, L. B. (Orgs.). Educação a distância e tutoria : considerações pedagógicas e práticas. Porto Alegre: Evangraf, 2013, p. 14-35. Disponível em: 〈http://hdl.handle.net/ 10183/109246>. Acesso em: 26 Maio 2016.

LEVY, P. A inteligência coletiva : por uma antropologia do ciberespaço. São Paulo : Edições Loyola, 1998.

LEVY, P. Cibercultura. São Paulo : Editora 34, 1999.

MOREIRA, M. A. Aprendizagem significativa: um conceito subjacente. In: Moreira, M.A.; Caballero, M.C. e Rodríguez, M.L. (Orgs.). Actas del Encuentro Internacional sobre el Aprendizaje Significativo. Burgos, España, 1997, p, 19-44. Disponível em: <http://www.if.ufrgs.br/ moreira/apsigsubport.pdf> . Acesso em: 30 Jun. 2016.

NOVAK, S. Educação a Distância e racionalidade educativa : a construção do entendimento na comunidade virtual de aprendizagem. Programa de Pós-Graduação em Educação/UFRGS, 2010. Tese de doutorado. Disponível em: <http://hdl.handle.net/10183/27676>. Acesso em: 26 Maio 2016. 
PAZ, J. C. S. S. Ensinar em comunidade virtual de aprendizagem : a emergência da presença de ensino distribuída no desenvolvimento de uma comunidade de investigação. Educação a Distância e Elearning/Universidade Aberta. Lisboa, Portugal, 2015. Tese de doutorado. Disponível em: <http://hdl.handle.net/10400.2/4993> . Acesso em: 26 Maio 2016.

PEREIRA, S. V. M. Interação em Fóruns de EAD: a otimização de um espaço de aprendizagem colaborativa. EUTOMIA : Revista Online de Literatura e Linguística, v. 1, n. 07, 2011. Disponível em: <http://www.repositorios.ufpe.br/revistas/index.php/EUTOMIA/article/view/ 1206/940>. Acesso em: 26 Maio 2016.

PRIMO, A. Interação mútua e reativa : uma proposta de estudo. Revista da Famecos, n.12, p.81-92 jun. 2000. Disponível em: 〈http://www.ufrgs.br/limc/PDFs/int_mutua_reativa.pdf >. Acesso em: 30 Maio 2016.

SABBATINI, M. Concepções e estratégias da aprendizagem participativa na educação a distância (EAD): contribuição das práticas dialógicas e comunicacionais para a autonomia discente. Revista Observatório, Palmas, v. 1, n. 3, p. 80-99, dez. 2015. Disponível em: 〈https://sistemas2.uft.edu.br:8004/index.php/observatorio/article/view/1538>. Acesso em: 26 Maio 2016. doi: http://dx.doi.org/10.20873/uft.2447-4266.2015v1n3p80.

SANTAELLA, L. Linguagens Líquidas na Era da Mobilidade. São Paulo: Paulus, 2007.

SARMENTO, D. F. A teoria histórico-cultural de L. S. Vygotsky e suas contribuições para as práticas educativas. SARMENTO; RAPOPORT; FOSSATTI (Orgs.). Psicologia da educação : perspectivas teóricas e implicações educacionais. Canoas: Salles, 2008, p.27-43.

SCHLEMMER, E. Dos Ambientes Virtuais de Aprendizagem aos Espaços de Convivência Digitais Virtuais - ECODIS: O que se mantêm? O que se modificou? VALENTINI, C. B.; SOARES, E. M. S. (Orgs.). Aprendizagem em ambientes virtuais: compartilhando ideias e construindo cenários. Caxias do Sul, RS: Educs, 2010, p. 145-191. Disponível em <http://www.ucs.br/etc/revistas/index.php/aprendizagem-ambientes-virtuais/article/view/ 393/323)>. Acesso em: 26 Maio 2016.

SCHERER, S. Comunidades virtuais de aprendizagem: habitantes, visitantes e transeuntes. In: $14^{\circ}$ Congresso Internacional ABED de Educação a Distância : Mapeando o Impacto da EAD na Cultura do Ensino-Aprendizagem. Santos, SP, setembro, 2008. Disponível em:

<http://www.abed.org.br/congresso2008/tc/511200835743PM.pdf〉. Acesso em: 26 Maio 2016.

SILVA, V. A dinâmica caleidoscópica do processo de aprendizagem colaborativa no contexto virtual : um estudo na perspectiva da complexidade/caos. Faculdade de Letras/ UFMG, 2008. Tese de doutorado. Disponível em: <http://www.bibliotecadigital.ufmg.br/ dspace/handle/1843/AIRR-7DDK65>. Acesso em: 26 Maio 2016.

SILVA, V. F. G. F. Comunidades DIY e aprendizagem colaborativa online. Faculdade de Ciências Sociais e Humanas/ Universidade Nova de Lisboa, 2015. Dissertação de mestrado. Disponível em: <https://run.unl.pt/handle/10362/16015>. Acesso em: 26 Maio 2016.

VIEIRA, L. M. M. Comunidades virtuais : um estudo do caso nos cursos de pós-graduação do NAVI/EA/UFRGS. Programa de Pós-Graduação em Administração/UFRGS, 2007. Dissertação de mestrado. Disponível em: <http://hdl.handle.net/10183/8772> . Acesso em: 26 Maio 2016.

ZANK, C.; BASSO, L. O.; PASSERINO, L. M. Interações Discursivas: conflitos necessários à construção do conhecimento em comunidades virtuais de aprendizagem. RENOTE - Revista Novas Tecnologias na Educação, CINTED-UFRGS, v. 6, n 1, dezembro, 2008. Disponível em: <http://seer.ufrgs.br/renote/article/view/14398>. Acesso em: 26 Maio 2016. 